\title{
Performance of Waste Cooking Oil on Aged Asphalt Mixture
}

\author{
Ramadhansyah Putra Jaya ${ }^{1 *}$, Romana Sarker Lopa ${ }^{2}$, Norhidayah Abdul Hassan ${ }^{2}$, Haryati \\ Yaacob $^{2}$, Mohamad Idris Ali ${ }^{1}$, Nor Hayati Abdul Hamid ${ }^{3}$ and Mohd Ezree Abdullah ${ }^{4}$ \\ ${ }^{1}$ Faculty of Civil Engineering and Earth Resources, Universiti Malaysia Pahang, 26300 Gambang, \\ Pahang, Malaysia \\ ${ }^{2}$ Faculty of Engineering, School of Civil Engineering, Universiti Teknologi Malaysia, 81310 UTM \\ Skudai, Johor Bahru, Malaysia \\ ${ }^{3}$ Institute for Infrastructure Engineering and Sustainable Management (IIESM), Universiti Teknologi \\ MARA, 40450 Shah Alam, Selangor, Malaysia \\ ${ }^{4}$ Faculty of Civil and Environmental Engineering, Universiti Tun Hussein Onn Malaysia, 86400 Batu \\ Pahat, Johor Bahru, Malaysia
}

\begin{abstract}
Asphaltic concrete pavement is popular worldwide, but this type of pavement requires frequent maintenance and rehabilitation as it cannot cope up with the increasing number of traffic vehicles and loads. Therefore, modifying asphalt pavement to reduce the damages and defects is necessary, thereby enhancing the serviceability of pavement. This study presents the effect of waste cooking oil on asphalt mixture at different ageing conditions. A 60/70 penetration-grade asphalt binder was used, and $5 \%$ of this binder was replaced with untreated and treated waste cooking oil. Asphalt mixtures were prepared at the selected 5\% optimum bitumen content and under two tests, i.e. Marshall stability and resilient modulus. The findings showed the better stability and resilient modulus of long-term aged samples incorporated with treated waste cooking oil than the unaged and short-term aged samples. The incorporation of untreated waste cooking oil caused reduced performance compared with the controlled and longterm aged samples. This result can be attributed to the high acid value of waste cooking oil. Therefore, treated waste cooking oil can be used as a binder replacement given its significantly higher performance at the mentioned ageing condition than the controlled mixture.
\end{abstract}

\section{Introduction}

Flexible or asphaltic concrete pavement is widely constructed throughout the world because it is relatively cheap and produces low noise compared with other paving methods. Asphaltic concrete is a mixture of aggregates and binder. Asphalt binder is used in road construction due to its several properties, i.e. waterproofing, thermoplastic, viscoelastic and

\footnotetext{
* Corresponding author: ramadhansyah@ump.edu.my
} 
rheological behaviour. Pavements experience increased traffic volume and load and heavy tire pressure from heavily loaded vehicles, which in turn damage the surface of the pavement. Other factors, such as climate change and extreme weathering condition, also contribute to pavement defects.

Numerous variables affect the viscoelastic properties of asphalt mixtures with time; age hardening may be considered one of the most important among these variables [1]. The term 'ageing' is often used to describe the process of 'hardening'. Ageing of asphalt mixture significantly affects the functionality and quality of pavement [2]. Excessive age hardening can significantly reduce flow capabilities of bitumen, resulting in brittleness [3]. This condition can reduce the effectiveness of the bituminous mixture to support traffic and excessive thermally induced stresses. Thus, modification is necessary to enhance the service life of pavement asphalt mixture.

The concept of using waste oil as a binder replacement is not new. Several studies have applied waste oil to modify asphalt mixture. Incorporation of waste oil aims to stabilise the properties of asphalt mixture during exposure to the atmosphere. Using waste cooking oil as a rejuvenating agent in reclaimed asphalt pavement (RAP) yielded positive results in reviving aged bitumen to its original state [4]. Waste cooking oil was also introduced as a rejuvenator to restore the properties of aged binder in porous asphalt [5].

From a previous study, waste cooking oil, as a binder replacement, can therefore be used to modify the asphalt mixture [6]. The use of waste cooking oil in asphalt mixture can reduce ageing characteristics by providing an improved serviceability, as the cooking oil undergoes several changes while frying, which can benefit the modification of the asphalt mixture. The quality of waste cooking oil may reduce the quality of bitumen because waste cooking oil is contaminated by impurities, such as water, polymers and free fatty acids, during cooking [7]. Incorporating waste cooking oil with asphalt mixture can prove economical, as this oil is unsuitable for human consumption after use and also cheaper than other available oils.

This study presents the performance of asphalt mixture incorporated with waste cooking oil at different ageing conditions. For this work, untreated and treated waste cooking oil were used to determine the performance of asphalt mixture.

\section{Materials and method}

\subsection{Aggregate and gradation}

Aggregates are the most mined materials in the world and are widely used for road construction. Two types of aggregates are used for pavement construction: coarse and fine aggregates. Coarse aggregates are portions of aggregate retained on a $2.36 \mathrm{~mm}$ sieve. Typical examples of coarse aggregates include crushed rocks and blast furnace slags. Fine aggregates comprise the aggregates retained between $2.36 \mathrm{~mm}$ and $75 \mu \mathrm{m}$ sieves. Typical examples of fine aggregate include sand, gravel, crushed stone and slag. Aggregates from Hanson Quarry were used throughout the study. The percentages of aggregates required for every sieve size were determined in accordance with JKR/SPJ/2008-S4. Fig. 1 shows the envelope limits of the selected gradation of AC14. 


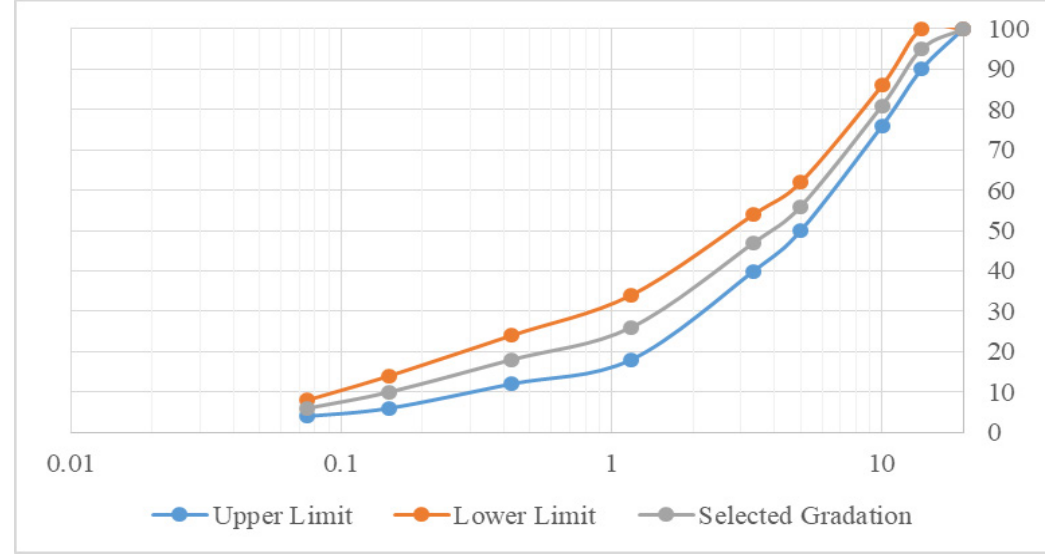

Fig. 1. Gradation Envelope limits for AC 14

\subsection{Bitumen}

The 60/70 asphalt binder was used in this study. This binder is often used as paving-grade bitumen, particularly in road construction and for superior-quality asphalt pavements. This particular bitumen is widely used for the manufacture of hot mix asphalts, which are often used for bases and wearing courses. Bitumen $(5 \%)$ was used to prepare the samples for the present study [7].

\subsection{Waste cooking oil}

For this study, untreated and treated waste cooking oils were used to observe the performance of asphalt mixture at different ageing conditions. Waste cooking oil, at 5\% weight of bitumen, was used to replace the conventional bitumen [7]. Waste cooking oil is contaminated with various impurities, such as water, polymer and free fatty acids. Oleic acid is present in the highest amount in waste cooking oil [8]. The untreated waste cooking oil was collected from a food court.

\subsection{Marshall mix design}

This test is conducted to determine the strength of a compacted asphalt mixture to a standard laboratory compact effort. This study was performed in accordance with ASTM D6927-15. The specimens were prepared by immersing in water bath at approximately 60 ${ }^{\circ} \mathrm{C}$ with a period of $45 \mathrm{~min}$. Then, the specimens were placed under the Marshall stability testing machine and loaded at a constant rate of $50.8 \mathrm{~mm} / \mathrm{min}$ deformation until the maximum load was obtained.

\subsection{Resilient modulus test}

Resilient modulus was used to evaluate the elasticity behaviour of the asphalt mixture under repetitive load. This test was identified as one of the main mechanistic design of pavement structure and conducted by using Material Testing Apparatus (MATTA). The dimension size of Marshall sample used in this study had an average of $66.0 \mathrm{~mm}$ and 101.0 for height 
and diameter measurement, respectively. A universal material testing apparatus is used to measure the indirect tensile strength by applying repeated loading or pulse. The test was conducted in accordance with ASTM D7369-11. This test was carried out at two temperatures i.e. $25^{\circ} \mathrm{C}$ and $40^{\circ} \mathrm{C}$.

\subsection{Ageing}

The ageing procedure of asphaltic mixture was adopted from the strategic highway research program as described in AASHTO R30-2 (2006). Separate specimens were prepared at the time of mixing to represent an unaged condition. These samples were left unconditioned. As soon as mixing was complete, the specimens were immediately compacted using a gyratory compactor. The short-term ageing conditioning can be applied to loose mixture only. The mixture was placed in a pan and spread in an even thickness ranging from $25 \mathrm{~mm}$ to $50 \mathrm{~mm}$. The mixture was placed in a faced draft oven for $4 \mathrm{~h} \pm 5 \mathrm{~min}$ at a temperature of $135 \pm 3{ }^{\circ} \mathrm{C}$. The mixture was stirred every $60 \pm 5 \mathrm{~min}$ to maintain uniform conditioning. After $4 \mathrm{~h}$, the samples were subjected to a compaction temperature and compacted using a Marshall compactor. The long-term ageing mixture conditioning procedure can be applied to laboratory-prepared samples following short-term ageing to plant-mixed ones [10]. Long-term ageing was performed on compacted specimens after they have been short-term aged. The samples were placed in an oven at $85{ }^{\circ} \mathrm{C}$ and then left for 5 days. After the ageing period, the oven was turned off and allowed to cool down to room temperature.

\section{Results and discussion}

\subsection{Stability}

Fig. 2 presents the results of the Marshall stability at various ageing conditions for the control, incorporated untreated and treated waste cooking oil samples. Results showed that the stability of unaged samples increased upon addition of waste cooking oil. In the case of the untreated sample, stability increased by $2 \%$ compared with the conventional asphalt mixture. For the treated sample, stability increased by $12 \%$ at a value of $15.05 \mathrm{KN}$. Test results showed that the short-term sample prepared using untreated waste cooking oil exhibited less stability than the conventional one although for the unaged condition, the value was higher than that for the conventional sample. However, when treated waste cooking oil was used, stability decreased by approximately 5\%. The long-term aged samples incorporated with treated waste cooking oil showed the highest stability compared with the unaged and short-term aged samples. The increase in stability was $32 \%$ higher than that of the control samples. On the other hand, the use of untreated waste cooking oil resulted in less stability by reducing the value by $18 \%$. From the results, the mixture prepared using treated waste cooking oil achieved higher stability than the other mixtures owing to its higher stiffness and less flow tendency. The mixture of untreated waste cooking oil showed low stability due to lubrication and high fluidity values [11]. The highest stability values were observed in the long-term samples with treated waste cooking oil, indicating the increased Marshall stiffness of the mixture. The Marshall stability of the long-term aged samples increased by $49 \%$ compared with that of short-term aged samples. The loss of volatiles may cause the increased stiffness of the mixture, which can then tolerate the excessive load coming from traffic operations [12]. 


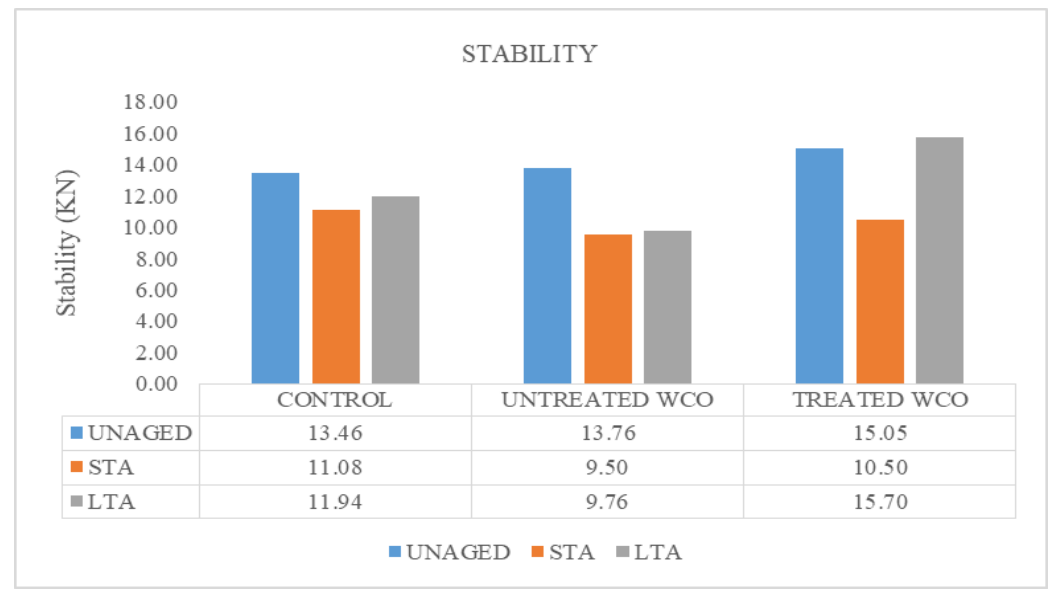

Fig. 2. Stability of asphalt mixture at different ageing conditions

\subsection{Resilient modulus}

\subsubsection{Resilient modulus at $25^{\circ} \mathrm{C}$}

Fig. 3 depicts the test results of resilient modulus for the different samples at varying ageing conditions and at $25^{\circ} \mathrm{C}$. The graph shows that the resilient values were influenced by the incorporation of untreated and treated waste cooking oil. The resilient modulus of asphalt mixture in unaged condition increased by $23 \%$ upon addition of treated waste cooking oil, but it decreased by $44 \%$ when untreated waste cooking oil was incorporated. Furthermore, the stiffness modulus of samples also increased with the replacement of treated waste cooking oil. Fig. 3 illustrates the results of the resilient modulus test at varying ageing conditions. From the test results of short-term samples, the resilient modulus increased with the replacement of 5\% treated waste cooking oil, but it decreased when untreated oil was used. This increase in resilient modulus was $2 \%$ higher than that for the conventionally mixed treated waste cooking oil, when untreated waste cooking oil was added to the mixture, resilient modulus decreased by $40 \%$. Long-term aged samples showed the highest resilient modulus for the asphalt mixtures compared with the unaged and short-term aged samples. Nine different samples were prepared for this test: three for $0 \%$ replacement of bitumen, three for $5 \%$ replacement with untreated waste cooking oil and three for treated waste cooking oil. The test results from the Fig. 3 show that for the mixture of treated waste cooking oil, the resilient modulus equalled $5758 \mathrm{MPa}$, which is $38 \%$ higher than that of the conventional asphalt mixture. On the other hand, resilient modulus decreased with the use of untreated waste cooking oil. 


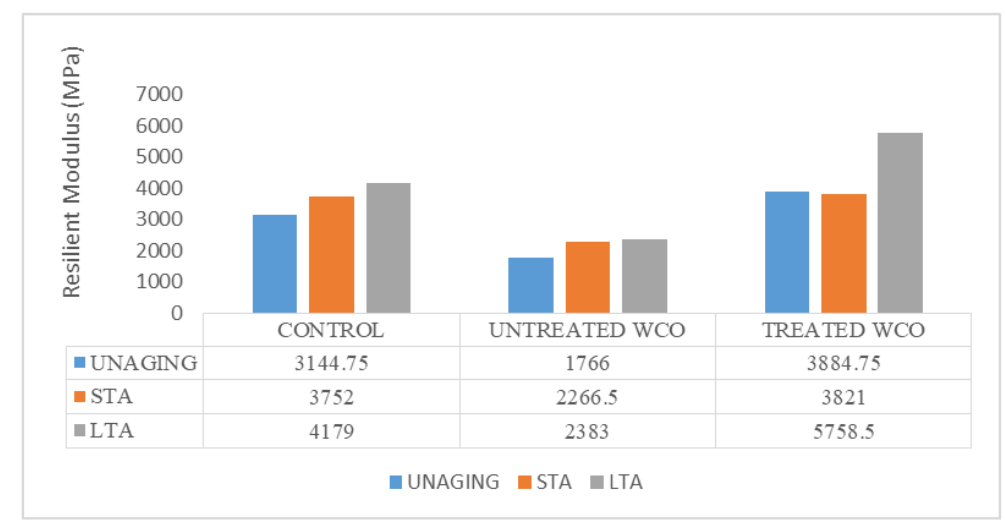

Fig. 3. Resilient Modulus vs Waste Cooking Oil at $25^{\circ} \mathrm{C}$

\subsubsection{Resilient modulus at $40^{\circ} \mathrm{C}$}

Fig. 4 shows the test results of resilient modulus at varying ageing conditions at a $40{ }^{\circ} \mathrm{C}$ temperature for the control, untreated and treated waste cooking oil. At $40{ }^{\circ} \mathrm{C}$ temperature, the resilient values were also influenced by the use of untreated and treated waste cooking oil. The resilient modulus of asphalt mixture in unaged condition increased by $12 \%$ compared with the conventional mixture after mixing with treated waste cooking oil, but it decreased by $12 \%$ when untreated waste cooking oil was incorporated. From the test results of short-term aged samples, resilient modulus was almost the same with the replacement of $5 \%$ treated waste cooking oil, but it decreased when untreated oil was used. This decrease reached $13 \%$ in comparison with that of the conventional mixture. Although long-term aged samples showed the highest resilient modulus for the asphalt mixtures compared with the unaged and short-term aged conditions, the change in resilient modulus for the replacement of treated waste cooking oil with bitumen showed no significance at an increase of $6 \%$. An increment in resilient modulus was observed when treated waste cooking oil was used at 25 ${ }^{\circ} \mathrm{C}$ and $40{ }^{\circ} \mathrm{C}$, but it decreased with the use of untreated waste cooking oil. Good bonding between the particles of binder and aggregates was produced when chemically modified waste cooking oil was used, and this bonding provided a hard mixture that can resist the influence of vehicle loading. In the case of the untreated waste cooking oil, a weak interlocking bonding formation was observed, resulting in the low durability of the asphalt mixture [11]. Resilient modulus increased with the increase in ageing period, and this increase was $51 \%$ higher for the long-term aged sample incorporated with treated waste cooking oil than that for short-term aged samples. This increment may be related to the increase in stiffness, whereas a high resilient modulus can generate significant resistance against rutting development in asphalt pavements $[12,13]$. 


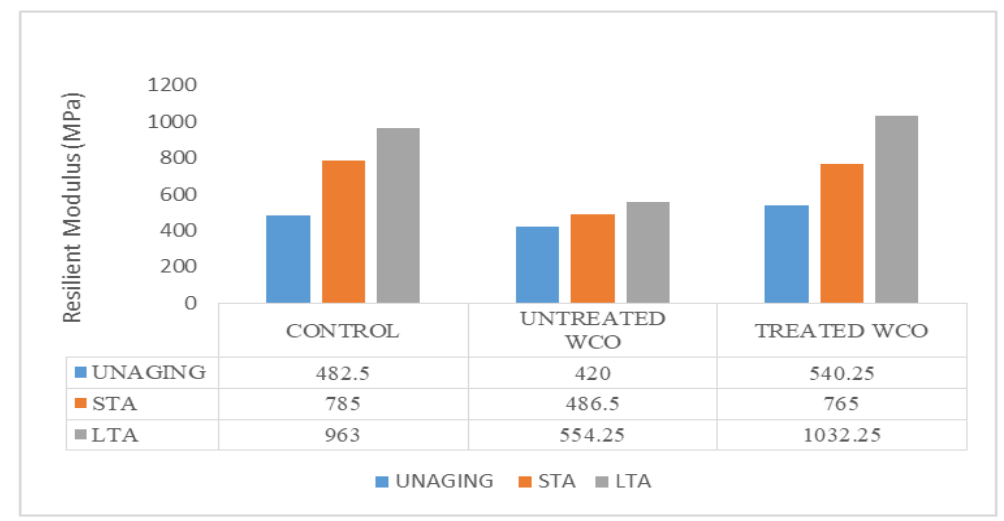

Fig. 4. Relationship between Resilient Modulus and Waste Cooking Oil at $40^{\circ} \mathrm{C}$

\section{Conclusions}

On the basis of the results obtained from data analysis, the performance of asphalt mixture was significantly influenced by the replacement of bitumen with waste cooking oil. The stability and resilient modulus increased when treated waste cooking oil was used, but the opposite results were observed with the use of untreated waste cooking oil. The decreased performance of the asphalt mixture was attributed to the high acid value of untreated waste cooking oil. With the use of treated waste cooking oil, all properties of the asphalt mixture increased by a significant percentage, and for long-term ageing, the results showed the highest increase. Thus, treated waste cooking oil can be used as a replacement of asphalt binder in asphalt mixtures given its higher performance in different ageing conditions in comparison with that of conventional mixtures.

Research work presented in this paper was supported by the Ministry of Higher Education Malaysia (MOHE) and Universiti Teknologi Malaysia (grant number Q.J130000.2522.18H05 and Q.J130000.2522.11H76). The financial assistance for this study is highly appreciated.

\section{References}

1. P. K. Das, KTH Royal Institute of Technology (2014).

2. F. M. Salah, Universiti Teknologi Malaysia (2016).

3. M. M. Rahman, G. D. Airey, A.C. Collop, Nottingham Centre for Pavement Engineering (2005).

4. H. Asli, M. R. Karim, Eastern Asia Society for Transportation Studies (2011).

5. W. N. A. W. Azahar, M. Bujang, R. P. Jaya, M. R. Hainin, N. Ngadi, M. E. Abdullah, A. A. Mohamed, . Jurnal Teknologi, 78(4), 105-109 (2016).

6. W. N. A. W. Azahar, M. Bujang, R. P. Jaya, M. R. Hainin, N. Ngadi, M. Mohamed, Key Engineering Materials, 700 (2016).

7. W. N. A. W. Azahar, R. P. Jaya, M. R. Hainin, M. Bujang, N. Ngadi, Construction and Building Materials, 126, 218-226 (2016).

8. N. H. M. Kamaruddin, M. R. Hainin, N. A. Hassan, M. E. Abdullaha, H. Yaacobb, Jurnal Teknologi, 71(3), 93-98 (2014).

9. A. Moghaddsi, Universiti Teknologi Malaysia (2013).

10. F. Yin, E. A. Mercado, A. E. Martin, D. Newcomb, N. Tran, Road Materials and Pavement Design, 18(sup1), 2-27 (2017). 
11. W. N. A. W. Azahar, R. P. Jaya, M. R. Hainin, M. Bujang, N. Ngadi, Construction and Building Materials, 150, 653-663 (2017).

12. S. I. Sarsam, S. M. Abdulmajeed, Jurnal of Engineering, 20, 12, (2014).

13. M. I. M. Yusak, Universiti Teknologi Malaysia (2012). 